\title{
Representation-based models in the current landscape of phonological theory
}

\author{
Katalin Balogné Bérces \\ Pázmány Péter Catholic University, Budapest; \\ Catholic University in Ružomberok \\ berces.katalin@btk.ppke.hu \\ Patrick Honeybone \\ University of Edinburgh \\ patrick.honeybone@ed.ac.uk
}

\begin{abstract}
We place the healthy diversity of current (i.e., early 21st-century) phonological theory under scrutiny, and identify the four fundamental approaches that make it up: Rule-Based Phonology, Representation-Based Phonology, Constraint-Based Phonology, and Usage-Based Phonology. We then focus on the key aspects of and recent developments in Representation-Based Phonology: we separate out hybrid models and purely representational ones, we identify Government Phonology (GP) as the most popular form of the latter (and show that it is even present in what we call 'GP-friendly' analyses), and finally, we discuss and illustrate recent innovations in both subsegmental and prosodic structure in the two strands that we identify as 'hyperhierarchical' (or 'vertical') and 'flat' (or 'horizontal').
\end{abstract}

Keywords: phonological theory; representations; phonological structure; autosegmental phonology; Government Phonology

\section{Introduction: the current landscape of phonological theory}

The current theoretical landscape in phonology (at the end of the second decade of the 21st century) is healthily diverse (cf. Hannahs \& Bosch 2017, chapter 1). One way to show this is to consider the presentations given at 'generalist' academic conferences dedicated to phonology. The largest annual phonology conference is the Manchester Phonology Meeting (the 'mfm' - see www.lel.ed.ac.uk/mfm), which has occurred each year for a quarter of a century, with a steady number of around 80 presentations in recent years, and with participation from all around the world. Sebregts (2017) analysed the presentations given at the first $25 \mathrm{mfms}$, and identified quite steady proportions of talks from a number of different theoretical perspectives over the last decade, with no individual perspective taking up 
much more than $40 \%$ of the presentations. This paper analyses this diversity of approach in the current landscape of phonological theory and recognises four fundamental strands. ${ }^{1}$ After a brief contextualisation of contemporary work in terms of its historical background, we set out these four approaches and consider the key characteristics of each, in section 2 . Sections 3 and 4 focus on one of them (which we call 'Representation-Based Phonology') in detail, as it rests on quite recent developments, and has not been described before in synoptic work on phonological theory: section 3 discusses its key concepts and principles, while section 4 introduces and illustrates its current strands and their innovations in subsegmental (section 4.1) and prosodic (section 4.2) structure. Finally, section 5 concludes.

\section{Four major currents in the contemporary phonological landscape ${ }^{2}$}

A major turning point in the development of the investigation of sound structure in human language came with the structuralist separation of phonetics and phonology. It was this move that led to the birth of autonomous (i.e., formal) phonology, which in turn enabled the inception of generative phonological theory in the seminal work of Chomsky and Halle in 1968 (SPE). One of the greatest merits of SPE's rule-based and linear model, however, was its very imperfection, which stimulated a flowering of formal phonological theory, which both provoked the rehabilitation of syllable structure in mainstream phonological theory, and led to the introduction of novel hierarchical organisation in autosegmental representations both below and above the syllabic tier. Quite soon after this, primarily due to their inability to handle conspiracies and missed generalisations, the very rules of the SPE model also came under attack, and an alternative view in which well-formedness constraints make up the core of grammar was proposed. By the 1990s, these events had led to a theoretical landscape made up of three major components: rules, representations, and constraints. Since then, there has occurred a 'loop' back to non-autonomous phonology, with the development of a strand of work where the analytical focus is directed towards usage-based factors

${ }^{1}$ There is a strict requirement for brevity in this paper, so we must ignore many details, but we hope that our basic analytical points make sense.

2 The discussion in this section heavily draws on Honeybone (2011). For an overview in Hungarian, see Balogné Bérces (2019). 
(phonetics, analogy, frequency). ${ }^{3}$ As a result, we can now identify four major currents in present-day phonological theory: Rule-Based Phonology (RBP), Representation-Based Phonology (RepBP), Constraint-Based Phonology (CBP), and Usage-Based-Phonology (UBP), all of which can be seen as diffuse 'theory groups'. Naming the currents in this way places emphasis on what is the most important thing for the understanding of phonology according to those who work in each framework. RBP, RepBP and CBP are fundamentally formal approaches to phonology, while UBP dissents on this issue.

All these currents are contemporary (and have been live throughout the current century), but they differ in their popularity, and a number of strands have developed within each basic current. As we mention above, the primary representative of RBP is the SPE model (also including developments such as Lexical Phonology); nowadays this approach is in the minority but it has several prominent current proponents (see, for example, Vaux 2008). The majority of present-day representatives of autonomous, formal phonology come from either a RepBP or a CBP background. The fundamental hallmark of RepBP is a subscription to autosegmentalism (see sections 3-4), and RepBP-type frameworks include two major related strands, Dependency Phonology (DP) and Government Phonology (GP), and currently form a substantial minority position in Europe (e.g., Scheer 2004), and a few other places. The largest, most popular and most populous contemporary framework in phonology is CBP, with Optimality Theory $(\mathrm{OT})^{4}$ as the primary (albeit not the only) representative (e.g., McCarthy 2001; Prince \& Smolensky 1993/2002/2004), while UBP presents a substantial minority position (e.g., Bybee 2001). The UBP movement is part of a twenty-first-century 'assault on autonomous phonology' (e.g., Port \& Leary 2005), and is characterised by eclecticism in its proponents and iconoclasm in its views - the strand of phonological work dubbed Exemplar Phonology (e.g., Pierrehumbert 2001) fits in here. ${ }^{5}$

${ }^{3}$ At the same time, the idea of a 'hyper-autonomous' phonological module has been pursued by proponents of Substance-Free Phonology. As pointed out by a reviewer, current RepBP is divided over the issue of substance in phonology and the universal nature of acoustic signatures. See Scheer (2019) and the papers in Chabot (to appear).

${ }^{4}$ Note that Uffmann (2011) treats all of GP, DP and OT as forms of constraint-based phonology, using the label to mean something like 'non-rule-based'. It may well be that the popularity of OT is now on the wane (see, for example van Oostendorp to appear), but the framework is still widely used and is being actively developed.

${ }^{5}$ For recent overviews of the four approaches (albeit not quite adopting the framework for understanding them set out here), see the chapters of Hannahs \& Bosch 
This model of the current landscape of phonological theory does not have a distinct place for 'Laboratory Phonology' (often called 'LabPhon'), which may strike the reader as mistaken, given that there is a clearly identifiable set of ideas and people who identify under this banner. We think that our four-way distinction is correct, however, as those identifying under the banner of Laboratory Phonology are fundamentally a 'methodology group', rather than a 'theory group', with a commitment to use experimental methods (often with acoustic measurements and statistical interpretation of results) to investigate phonological issues. As such, work in LabPhon typically requires a theory to generate questions to test, and this theory could be either of the four currents of theory set out above, so LabPhon work could be RBP, RepBP, CBP or UBP.

In order to briefly illustrate the basic mechanism of each of the four major currents of theory just identified, in order to compare their analytical methods and exemplify the differences they display, we turn to the German data in (1), meant as an example of some classic data of the type that phonologists frequently fall back on.

(1) The alternation of voiced and voiceless obstruents in base-final position in German ${ }^{6}$

\begin{tabular}{|c|c|c|c|}
\hline $\begin{array}{l}\text { Word-final } \\
\text { [lo:p] }\end{array}$ & $\begin{array}{l}\text { Pre-vocalic } \\
\text { [lo:bəs] }\end{array}$ & $\begin{array}{l}\text { Word-final } \\
\text { [rap] }\end{array}$ & $\begin{array}{l}\text { Pre-vocalic } \\
\text { [rapəs] }\end{array}$ \\
\hline [bunt] & [bundəs] & [bunt] & [buntəs] \\
\hline [ve:k] & [ve:gəs] & [rok] & [rokəs] \\
\hline [bra:f] & [bra:vəs] & [Starf $]$ & [ taifəs] \\
\hline [havs] & [havzəs] & [vais] & [vaisəs] \\
\hline
\end{tabular}

Autonomous, formal approaches typically have in common a clear role for distinct phonological levels: at the underlying level, predictable characteristics and variation are stripped away, whereas, at the surface level, the distribution of segments can be predictable. Thus, for the words in the first column, like Bund 'federation', for instance, it is standard to identify the underlying representation/bond/, which has two corresponding surface realisations [bunt] (when final) and [bond-] (when prevocalic) - this contrasts with words like bunt (and others in the third column), which

(2017): $\mathrm{CBP} / \mathrm{OT}$ in chapters $2-5, \mathrm{RBP}$ in chapters $6-8$, RepBP in chapters 9-12, and connectionist theories and UBP in chapters 13-14 and 18-23.

${ }^{6}$ Glosses: Lob 'praise', Bund 'federation', Weg 'path', brav 'well-behaved', Haus 'house', Rap 'rap music', bunt 'colourful', Rock 'skirt', steif 'stiff', weiß 'white'. The first column for each morpheme gives a nominative or predicative uninflected form, and the second column a genitive or nominative neuter inflected form (the inflected form given for Rap would be jocular). 
do not alternate, and which thus have underlying final fortis segments. In RBP, the basic generalisation that there are no word-final voiced obstruents in German is expressed as a dynamic rule, which can affect underlying representations:

(2) $[$ +voice $] \rightarrow[$-voice $] /[\#$

Next, we illustrate CBP in the guise of OT. OT essentially assumes underlying ('input') and surface ('output') mappings like RBP, but (unlike RBP) it derives input-output pairs using a set of constraints on surface/output forms, ranked in order of how bad it is to violate them. There are (i) markedness constraints, which penalise specific configurations in the surface/output forms (cf. *FOV in the derivation of the German data, in (3)), and which conflict with (ii) faithfulness constraints, which penalise differences between underlying and surface forms (see the examples in (4)). The OT tableaux in (5) illustrate how the evaluation process weighs up a set of candidate outputs.

(3) *FinalObstruent/Voice (*FOV)

= final obstruents may not be specified $[+$ voice $]$

(4) IDENT(voice)

$=$ the value of [voice] must be the same in input and output

MAX

$=$ everything in the input must have a correspondent in the output, ruling out deletion

(5) OT tableaux illustrating the process of candidate evaluation

\begin{tabular}{|c|c|c|c|}
\hline /bund/ & $* \mathrm{FOV}$ & MAX & IDENT(voice) \\
\hline bund & * & & \\
\hline bunt & & & * \\
\hline bun & & * & \\
\hline /bund+əs/ & $* \mathrm{FOV}$ & MaX & IDENT(voice) \\
\hline \multicolumn{4}{|l|}{ bun.dəs } \\
\hline bひn.təs & & & * \\
\hline bひ.nəs & & $*$ & \\
\hline
\end{tabular}

The candidate which is calculated to be optimal (for the given grammar, under the circumstances created by the given constraint ranking), indicated by the pointing finger (๘), is not ideal as it, too, typically violates a set of constraints (constraint violations are indicated by an asterisk); 
in fact, it may turn out to be non-optimal in a different grammar with a different constraint ranking (e.g., that of English), where the low ranking of ${ }^{*}$ FOV will render IDENT(voice) fatal to violate. ${ }^{7}$

While OT typically pays no special attention to what phonological objects the input and the candidates are composed of (note the simple use of phonetic symbols to represent segments), this is the very issue that is at the heart of RepBP, which focuses on the make-up of the segments involved and the representation of the phonological environment in which a pattern occurs. A fundamental assumption in mainstream RepBP is that there is always a direct link between the structural description of a structural change (i.e., the context in which it occurs) and the change itself. ${ }^{8}$ In the specific case of the German data in (1), the phonetic form of the obstruent derives from its syllabic affiliation on a RepBP approach: prevocalic consonants ('onsets') are strong (or: licensed), which ensures that they remain stable in their subsegmental make-up in, e.g., [bon.dəs]; whereas syllable-final consonants in examples like [bunt] are weak (in GP and a few similar models, such consonants are in fact followed by an empty nucleus, i.e., /bon.d__/ and are weak because they inherit the empty nucleus' diminished capacity for maintaining phonetic material), and are therefore likely to lenite (decompose). In autosegmental terms, weak licensing leads to the delinking of subsegmental material ('voice', or its equivalent; in classical forms of GP's Element Theory, this is the privative element $|\mathrm{L}|)$. As we show in the next section, the other major autosegmental mechanism is spreading, which creates the link between context and change in the representation in assimilatory processes.

Finally, let us turn to UBP. Not being a formal approach, UBP tends to use rules as informal statements of patterns, but in its strictest form, there are no psychologically real alternations. There are only a vast number of exemplars of word forms stored in the lexicon, i.e., e.g., [bunt] and [bundes]; word-forms may be linked psychologically, but not through phonological derivation. Segment-sized generalisations are often thought to be made over these exemplars and, while potentially category-like, these generalisations are expected to be subject to gradient generalisations. The focus in a UBP approach to the data in (1) is on questions like (i) is there really full neutralisation? (ii) do some words not undergo the phenomenon

${ }^{7}$ For the purposes of compact demonstration, both the facts and the description are oversimplified - English, too, exhibits some form of obstruent voicelessness in lenes. See the literature produced by proponents of laryngeal realism, mentioned in section 4, e.g., Honeybone (2005); Huber \& Balogné Bérces (2010).

${ }^{8}$ See the discussion of the concept of the local source in sections $3-4$. 
(as much as others)? (iii) can statistical modelling help us understand the phenomenon?

As may be clear from the above discussion, RBP, RepBP and CBP are commensurable, as all three are forms of formal approaches to a phonology that is regarded as autonomous and as a mechanism deriving surface forms from underlying structures. According to these currents, phonological categories are expected to typically behave categorically, whereas UBP insists that gradience is not a negligible aspect of language use but is in fact expected in all phonological generalisations. While UBP assigns no role at all, and both $\mathrm{RBP}$ and $\mathrm{CBP}$ typically assign little role, to complex phonological representations (although hybrid models, such as C\&RepBP, for example, exist), RepBP puts the vast majority of the explanatory load in phonology on the shoulders of the structural configuration.

\section{Key concepts and principles of representation-based phonological models}

This brief section introduces some further key concepts of RepBP (which will be the focus of the rest of the article, as explained above, because it has not much been analysed in generalising work such as this), highlighting issues in terms of which it is (or claims to be) more successful than the other frameworks.

The fundamental principle of RepBP is the following: sound patterns and processes can be described, and their workings (including triggers, targets and outputs) explained, with reference to hierarchical structure that can be represented by tree diagrams (relations of association between higher-order and lower-order constituents). The degree to which association is constrained varies: the upper limit is sometimes set to binary (e.g., in GP) but typically zero is accepted as the lower limit (i.e., the absence of association - already early autosegmental phonology included empty categories/nodes and floating segments; latterly, empty categories have proliferated in GP). It aims to remain formal (unlike UBP); so that the analysis ensures falsifiability and avoids overgeneration. Below, we devote some space to this latter issue.

Analysts do not agree on how important overgeneration is, that is: whether it is important to worry about whether a framework predicts to be possible more than actually occurs (so much so that it is not even considered as a relevant issue in $\mathrm{UBP}$ or some versions of $\mathrm{CBP} / \mathrm{OT}$ ). However, it has been the main motor behind the emergence of autosegmental phonology ever since its inception. It is what has led to the introduction 
of the concept of the local source (emphasised repeatedly in GP as the 'Non-Arbitrariness Principle'; 9 see section 4 for more detail), and to the general acceptance within RepBP of the claim that overgeneration may be conceived of as 'missing the point'. If we invoke the simple example of laryngeal assimilation to illustrate the argument: a rewrite rule for this pattern is easy to write in RBP, as in (6a) - this works, but it can be seen to miss the point in a way that is best shown by the fact that the formalism allows the rule in (6b), too, just as easily.

(6) a. $[+$ voice $] \rightarrow[$-voice $] /[$ [-voice $]$

b. $[+$ voice $] \rightarrow[$-voice $] /[$ [

A crucial difference between (6a) and (6b) is that, while (6a) describes a cross-linguistically widespread pattern, $(6 \mathrm{~b})$ is not attested. The rewrite rules of SPE/RBP, therefore, heavily overgenerate, and were as a result largely replaced by the mechanism of spreading in representational, autosegmental approaches, in which the impossible pattern is simply unformulable. Anything unformulable (either totally or without crossing branches) is predicted to be ill-formed, or at least highly marked. In this way, the strict adherence to autosegmentalism in RepBP with the requirement of a link between context and change helps it avoid overgeneration (and, in fact, forces it to undergenerate in many cases), granting it a relatively high degree of explanatory adequacy.

\section{Current strands in RepBP}

In the discussion of current strands in RepBP, it is highly relevant that phonology in general has two major aspects: processes/computation ${ }^{10}$ and representations. SPE expressed clearly defined principles underlying both components: computation is serial (with rewrite rules being 'chronologically' ordered with respect to each other, producing multi-stage chains of derivation with intermediate representations - defining 'derivational' phonological theory), while representation is simply composed of unordered bundles of binary features (feature matrices) and boundary markers (e.g., \#) organised in a linear sequence 'like beads on a string'. Since

9 'There is a direct relation between a phonological process and the context in which it occurs' (Kaye et al. 1990, 194).

10 The traditional generative phonological term is 'rules', but that is already theory-specific, cf. the discussion above. 
SPE, the two components have developed in a parallel fashion in formal phonology, with analysts concentrating on either one or the other: arguing for constraints and against rules (or vice versa) irrespective of the representations of the constituents the rules/constraints manipulate; or arguing for certain representations (e.g., for empty categories) and against others (e.g., against the theoretical relevance of the syllable or the coda) without even sketching out how they envisage phonological computation, or simply wording the computational or interpretational instructions as informal statements (e.g., 'the spreading of element $|\mathrm{I}|$ causes palatalisation', or 'an unlicensed empty nucleus is phonetically interpreted as schwa').

This is possible because a given analysis does not need to introduce modifications and innovations in both modules. As a matter of fact, a strict adherence to autosegmentalism with its requirement of a local source makes a separate computational module largely unnecessary - processes apply iff (and as soon as) the local source is present. Still, theoretically at least, any theory of representation can be coupled with any theory of computation. ${ }^{11}$ In the present-day perspective, for example, CBP as a purely computational framework with no well-defined model of representations of its own, is able to receive any type of representations fed into its mechanism (allowing for hybrid models, as mentioned above). Therefore there exists a plethora of representations of different types that pop up in CBP (which for the most part means OT) analyses; typically, these are rather 'traditional' or 'standard' in nature: binary (or occasionally unary) features of mainstream feature theory composing segments, which are organised into a prosodic hierarchy of the constituents of standard syllable theory or Prosodic Phonology (Nespor \& Vogel 1986). ${ }^{12}$

Although in most cases it is a primarily OT analysis that adopts some representations, less frequently a representational model adopts OT as its procedural mechanism. There have been, for instance, attempts to feed GP representations into OT-like computations (Polgárdi 1998; 2015; Blaho \& Szentgyörgyi 2003; Faust \& Smolensky 2017; Faust \& Torres-Tamarit 2017), but they have mostly met with objections (to say the least) from GP circles and indifference from the side of OT.

11 The same point is made in Scheer \& Kula (2017).

${ }^{12}$ Declarative Phonology, whose major claim is that phonology should be nonderivational and any kind of feature-changing or feature-removal from the input is illegitimate (and therefore lexical entries are highly underspecified), also bases its representations on rather orthodox components of feature and syllable theory (Lodge 2009; Neef 2018), which makes it, too, a framework primarily focussing on issues of computation. For OT analyses making use of less traditional representations, see, e.g., Torres-Tamarit \& Hermans (2017); Zimmermann (2017).

Acta Linguistica Academica 67, 2020 
Outside GP, however, OT has largely become the default choice as the analytical framework in formal work: models of representation that are not associated with any particular model of computation regularly choose to be couched in OT. For example, scholars from the Toronto School (arguing that phonological features are organised into contrastive hierarchies, which are representations of universal markedness relations on the one hand, and language-specific segment inventories on the other - Hall 2007; Dresher 2009) ${ }^{13}$ have shown that the contrastive hierarchy lends itself very easily to formulation in terms of a set of constraints (cf. esp. chapter 6 of Dresher 2009). Another example is the theory of laryngeal realism (LR), which claims that the phonetic difference observed between aspiration languages like Germanic and true voice languages like Slavic has phonological relevance and should consequently be integrated into the model of a language's laryngeal phonology. The purely phonological [ \pm voice] of SPE is therefore replaced with some kind of representation of [aspiration/spread glottis] in languages of the former type and [voice] in the latter, and the representations can be fed into an OT mechanism (Petrova et al. 2006; Huszthy 2016).

The claim that computation and representations are two separate modules of phonology and as a consequence any theory of representation should be freely combinable with any theory of computation finds further support in the alternative ways in which the theories of representations mentioned above have been adapted. For example, the contrastive hierarchies of the Toronto School are often coupled with RBP; LR has also been applied in GP (in an early form in Harris 1994, and in a framework that explicitly identifies itself as LR in, e.g., Huber \& Balogné Bérces 2010) and GP-like models (Cyran 2014). In addition, many forms of suprasegmental phonology including metrical phonology, intonational phonology and tonal phonology are fundamentally representation-based in nature, but analysts will necessarily choose one or another theory of computation (RBP or $\mathrm{CBP}$ ) that will manipulate their representations during the derivation.

As is clear from the above discussion, these current strands in RepBP that combine with other frameworks to produce hybrid models contribute to a large extent to the diversity of approach characterising the presentday landscape of phonological theory. However, this diversity becomes even more apparent when we consider non-hybrid, purely representational models. These are representation-only frameworks, which are characterised by

${ }^{13}$ Contrastive hierarchy theory is typically based on binary phonological features. For a proposal to extend it to a set of unary primes (elements claimed to be directly related to the particles of Schane 1984), see Carvalho (2011) and Sandstedt (2018). 
what is referred to above as a strict adherence to autosegmentalism, and which, accordingly, need no expansive separate mechanism for computation as part of the model. GP serves as a straightforward illustration, whose explicitly pronounced view is that as long as the input (i.e. the lexical representation) is properly formulated/reconstructed, rules/processes automatically apply whenever their conditions are met (the 'Minimality Hypothesis', Kaye 1992, 141) - that is, analyses simply identify the local source, and give the computational or interpretational instructions as informal statements. This approach rules out extrinsic rule ordering but not necessarily intrinsic rule ordering (allowing for feeding rule order; cf. Harris \& Kaye 1990), and it is in this sense that it can be regarded as 'non-derivational'. ${ }^{14}$

In purely representational models, both the requirement of the local source (in GP, the Non-Arbitrariness Principle) and the rejection of extrinsic rule ordering (in GP, due to the Minimality Hypothesis) stem from the assumption that our model of phonological knowledge should be constrained enough to avoid overgeneration and make predictions that are falsifiable (cf. section 3 above). In fact, it is the recognition that there is always a local source in phonological events that leads RepBP to be input-oriented as well as to deny the existence of exceptions and 'crazy rules'. ${ }^{15}$ Also, the notion of the local source is central to RepBP's classification of phonological phenomena into two basic types (and its ruling out other types, like RBP's simple 'feature-changing rules') - assimilations and lenitions. In assimilations, the local source is a melodic prime/feature geometrical node which is local (i.e., adjacent to the target) on the relevant tier/projection in the hierarchy - what happens is spreading (cf. the example of laryngeal assimilation given in section 3). In lenitions (segmental weakening processes), on the other hand, the local source is the inherent prosodic weakness of the position that the target segment occupies (leading to weak or no licensing) - what happens is delinking (i.e., the loss of the association) or segmental decomposition (cf. the German case study in section 2).

In what follows, we will consider some of the manifestations of these principles, mentioning their major representatives as present in the phonological literature of the 2010's but concentrating on their most recent

${ }^{14}$ In fact, as pointed out by a reviewer, even these purely representational models are not purely representational in the sense that they are not without computation - of course, events like spreading, de- linking, or rule ordering (however intrinsic) require computation, even if it is automatic.

15 On 'exceptions' and 'crazy rules', see Scheer (2015; 2019), and Chabot (to appear), though. 
developments. Due to their dominance in non-canonical representations, we will focus on the (related) forms of DP, Radical CV Phonology (RcvP), and GP, the most popular member of the RepBP family. We will also see that the current popularity of GP, at least on the European scene of phonological modelling, is not only rooted in the lingering of the many subbranches of GP proper, but it is also supplemented by the emergence of 'GP-friendly' analyses, which arise from analysts who, despite not being proclaimed proponents of GP, occasionally adopt certain components thereof: typically, they accept GP-type empty categories in prosodic structure and/or adopt Element Theory's privative prime model of subsegmental structure.

The upcoming discussion will deal with melodic representations first (section 4.1), and will turn to prosodic structure at the end of the paper (4.2). As it will turn out, however, this traditional division into melody and prosody is not without problems, since a number of solutions qualify for being mentioned in both sections. This is for either of two reasons. First, certain theories claim that the two dimensions of phonology are uniform in the sense that they utilise the same primitives: RcvP provides a straightforward example of this, proposing that both aspects of phonological constituents can be represented in terms of but two primes (' $\mathrm{C}$ ' and ' $\mathrm{V}$ ', hence the model's name), which are subsegmentally grouped into three sets (place, manner and laryngeal), and which also serve as the prosodic constituents into which segments are organised. As a result, RcvP is mentioned in both sections. Second, certain theoretical frameworks are less easy to place in a rigorous melody-prosody division because the configurations they offer contain no boundary between those two dimensions, and they propose a single unified phonological structure; as we will see below, this is the fundamental property of the models dubbed 'hyperhierarchical'. Since such approaches innovate more in terms of multi-layered configurations familiar from prosody (and typically employ some radically reduced form of ET for what they claim remains melodic in nature); they are discussed in section 4.2.

\subsection{Subsegmental structure}

Segment-internal, melodic representations in current RepBP share a number of general properties, some of which are the following. First, they accept the 'one-mouth' principle (Harris 1994, 118), i.e., they employ the same set of melodic primes for the representation of consonants and vowels, or at least there is a considerable overlap between the two sets. Second, they claim that all primes are unary/monovalent/privative, which receive 
direct phonetic interpretation in both simplex and complex phonological expressions (partly rooted in Particle Theory - Schane 1984). Third, they assume segment-internal dependency relations (typically in the form of headedness, which is sometimes accompanied by some kind of melodic geometry) - one of the reasons for van der Hulst (2011) to call such models 'dependency-based phonologies'.

The theoretical frameworks that belong here are DP (Anderson \& Ewen 1987; more recently, e.g., Anderson 2011 and Navarro 2018; for a summary, see van der Hulst \& van de Weijer 2017), RcvP (a development of DP; van der Hulst 1994 et seq; most recently, 2018; van der Hulst \& van de Weijer 2018), and Element Theory (ET; GP's primary model of segment-internal structure). Since its first appearance in Kaye et al. (1985), ET has undergone various revisions (one of the earliest is in fact explicitly referred to as Revised ET), which space restrictions prevent us from introducing. For recent overviews, see Backley $(2011 ; 2012)$ about ET; Scheer \& Kula (2017) about both ET and RcvP. Most ET applications illustrate its use with no element geometry envisaged as part of the model; however, in certain recent versions as well as in DP and RcvP, elements are organised into intricate structures with multi-layered, three-dimensional configurations. For instance, based on the insights of RcvP, such an approach is sketched out in Kula (2002) and (2012), which have in turn inspired Liu (2017) and Kula \& Liu (2020). Within GP, element organisation into some kind of geometry was first proposed as early as in Harris (1994) but remained largely uninfluential until the idea of segment-internal organisation was taken up again in the form of a grid of tiers in Nasukawa \& Backley (2005; slightly revised and recycled for the purposes of LR in Huber \& Balogné Bérces 2010), and in the form of non-segmental representations with a unified prosody-melody hierarchy of the GP2.0 type (see next section). A few illustrations are given in (7) for comparison.

(7) Multi-layered subsegmental geometries

a. Harris $(1994,129)$

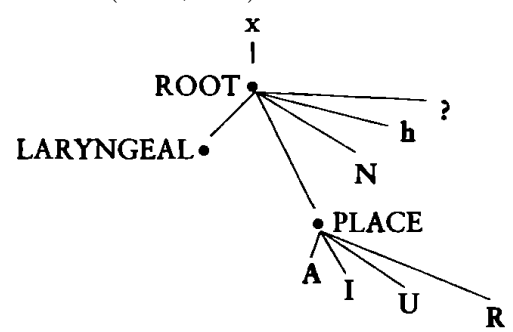

(LARYNGEAL hosts $|\mathrm{L}|$ or $|\mathrm{H}|$ depending on language type as in LR) 
b. Nasukawa \& Backley $(2005)^{16}$

i. for consonants:

ii. for vowels:

$\begin{array}{lclc} & \{\mathbf{h}, \mathbf{P}\}=\mathrm{X} & \text { FUndamental } & \{\mathbf{A}\}=\mathrm{X} \\ \text { SOURCE } & \mid \mathbf{L}, \mathbf{H}\} & \text { RESONANCE } & \{\mathbf{I}, \mathbf{U}\} \\ & \mid & & \mid \\ \text { RESONANCE } & \{\mathbf{I}, \mathbf{U}\} & \text { SOURCE } & \{\mathbf{L}, \mathbf{H}\} \\ & \mid & & \mid \\ \text { FUndamental } & \{\mathbf{A}\} & \text { EDGE } & \{\mathbf{h}, \mathbf{P}\}\end{array}$

c. Dependency Phonology (van der Hulst \& van de Weijer 2017, 335) ${ }^{17}$ segment
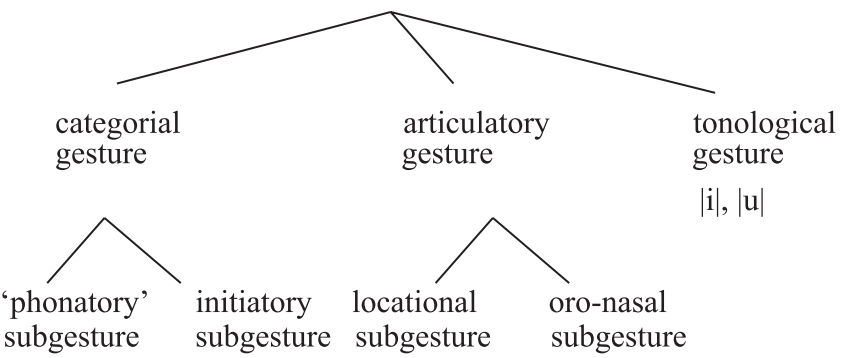

$$
|\mathrm{C}|,|\mathrm{V}| \quad|\mathrm{O}|,|\mathrm{G}|,|\mathrm{K}| \quad|\mathrm{a}|,|\mathrm{i}|,|\mathrm{u}| \ldots \quad|\mathrm{n}|
$$

d. 3D view of the geometry in Liu (2017)

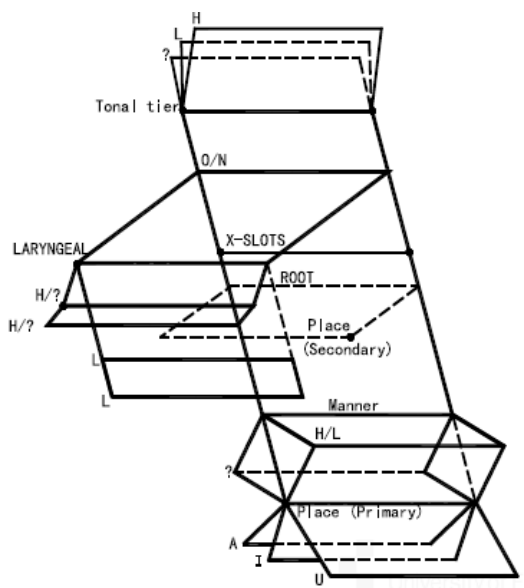

${ }^{16}$ From Huber \& Balogné Bérces (2010, 451).

17 The term 'phonatory' is in quote marks because the authors regard its use unfortunate; this gesture primarily defines major class and manner properties (i.e., the segment's place on the 'sonority scale'). 
As (7) shows, these models still maintain a relatively large set of melodic primes, which is accompanied by a geometric design of varying complexity. However, subsegmental hierarchy (and, in fact, autosegmentalism in general) has for a long time been fed from at least two independent sources: first, the observation that phonological features group into subsets, which determines their behaviour, and therefore melodic geometry is inevitable; and second, the argument that many phonological properties previously thought to be substantive (and thus represented by primes) are in fact structural in nature. That is, some of the analytical burden carried by phonetically-based primes can be taken over by the structural configuration which is needed anyway. As a result, it is apparent in recent trends that substance and structural configuration (branching) balance out: the more structure is proposed, the fewer primes are needed; and vice versa: the fewer primes are assumed, the more structure is introduced. All of these insights, coupled with the ever-existing ambition in ET to reduce the number of primes so that the model's predictive power is sufficiently constrained, have led some of the representation-oriented phonologists to introduce the 'hyperhierarchical' structures discussed in the next section.

Nevertheless, the non-geometrical view of ET continues to be the default framework used for melodic representations in forms of GP (cf. the 'flat' models of prosody in the next section), and ET as such seems to have become the default choice even for non-GP analysts aiming to utilise a non-canonical model of segment-internal structure, producing 'GP-friendly' models and analyses: new proposals that take the representations of dependency-based phonologies as the point of departure (e.g., Cavirani \& van Oostendorp 2020); or discussions of general, melody-related theoretical issues and/or issues of the interpretation of empirical facts which (primarily) consider them from the perspective of ET representations (e.g., Szigetvári 2020). ET seems to be on the rise as the new lingua franca for a wide segment of the RepBP community.

\subsection{Prosodic structure}

Supra-melodic representations in current RepBP are characterised by (i) the denial of canonical (constituents of) syllable structure; (ii) the recognition (or even proliferation) of empty categories; and (iii) dependency/licensing relations between heads (governors, licensors) and dependents (governees, licensees) - the other reason for van der Hulst (2011) to dub all of DP, RcvP and GP 'dependency-based phonologies'. These properties are exemplified by the German case study in section 2 above 
(from GP) as well as the dependency graph in (8) (from DP - Anderson 2011, cited in van der Hulst \& van de Weijer 2017, 347).

(8) Dependency graph for city, illustrating ambisyllabicity in DP

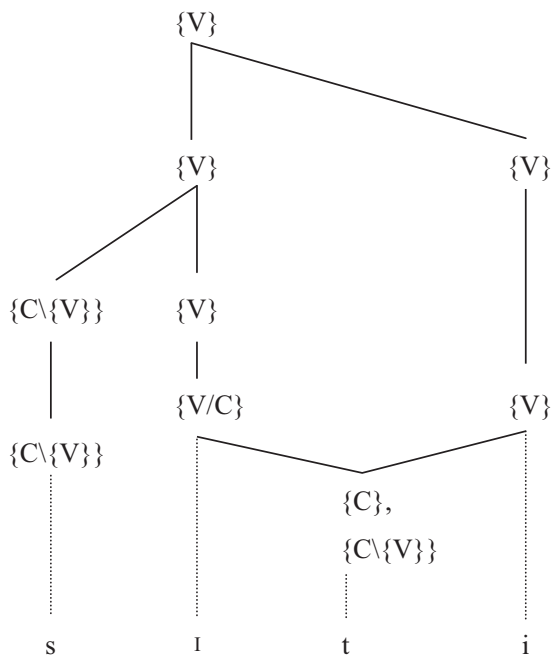

Although GP in its 'standard' or 'classical' form (dubbed standard Government Phonology (SGP) by some and GP1.0 by others) still survives in occasional publications like Charette (2017), most of GP's current forms display the trend discussed at the end of the preceding section, 'aim[ing] at reducing substance by exploiting structure' (Cavirani \& van Oostendorp 2020). There appear to be two directions to do so, and therefore there are two extreme views with respect to the general design of sound structure in contemporary RepBP: ${ }^{18}$ a 'flat'/'horizontal' model, placing the structural burden on empty categories and lateral dependency relations rather than multi-layered hierarchies, and a number of 'hyperhierarchical'/'vertical' models, stemming from the considerations mentioned in the previous section (and pushing the limits of 'exploiting structure' to its extremes) but ultimately rooted in a long but not particularly widespread tradition in generative phonology to conceive of the syllable as the maximal projection of the nucleus. ${ }^{19}$ Such x-bar (i.e., N-bar) models of syllable structure (as part of the so-called structural analogy argument, pinpointing parallelisms

${ }^{18}$ For a recent, concise summary of the history of prosodic structure in standard GP and of CVCV phonology, see Scheer \& Cyran (2017).

${ }^{19}$ As noted by a reviewer, the division into 'horizontal' vs. 'vertical' models coincides with the difference between a strict separation of structure and melody vs. no split 
between phonology and syntax - see Bermúdez-Otero \& Honeybone 2006) have been around since the 1980's, and are not only found in forms of GP - note that the dependency graph in (8) above is also an example thereof. Neither are such radically structural approaches particularly novel to GP: already in Rennison \& Neubarth (2003), all structural relations are defined by the x-bar theoretic principle that heads project and stand in an asymmetric relation to their specifiers and complements. What marks the more recent developments to be discussed presently as special is that they are non-segmental, too, in the sense that they offer a unified melody-prosody hierarchy in which the two are not discrete components, and not only are traditional prosodic units such as nucleus, mora, rhyme, syllable and foot epiphenomenal but the segment is not a constituent, either: it is difficult (if not impossible) to delineate the sound segments, which the symbols of phonetic transcriptions idealise into discrete objects, in their representations.

The hyperhierarchical or vertical models include GP2.0 (Pöchtrager 2006 et seq.; most recently, 2020; Tifrit \& Voeltzel 2016; Živanović 2020), Precedence-free Phonology (PfP - Nasukawa 2011 et seq.; most recently, 2019), as well as certain 'GP-friendly' approaches like the Onset Prominence (OP) representational framework (Schwartz, a number of publications; most recently, 2019). A fundamental principle that underlies these models is the re-interpretation of manner as structure (roughly, the more layers a structure has, the less sonorous the segment is), and only the place of articulation remains melodic (represented by elements associated in various ways to the nodes of the tree diagram). In GP2.0, even the element $|\mathrm{A}|$ (corresponding to [low] and [coronal]) is replaced by extra structure in the configuration, while laryngeal features may be regarded as either structural (GP2.0) or partly structural (PfP, OP). Both PfP and OP build the insights of Modulation Theory (Traunmüller 1994) into their representations. The representations of fortis plosives in the three frameworks are cited in (9) for comparison.

(9) Fortis plosives in 'vertical' models

a. Fortis /p/ in GP2.0 (Pöchtrager 2006, 70, 97)

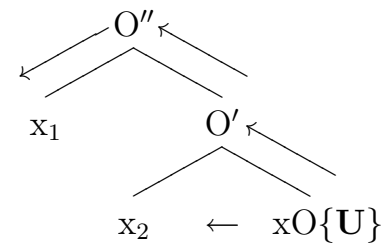

between melodic and structural levels, mentioned above as a source of difficulty in classifying models into either section 4.1 or section 4.2 .

Acta Linguistica Academica 67, 2020 
b. Aspirated /p/ in OP (Schwartz 2017, 9) $)^{20}$

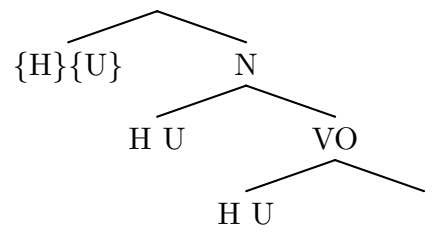

c. Aspirated /k/ in PfP (Nasukawa 2017, 44)

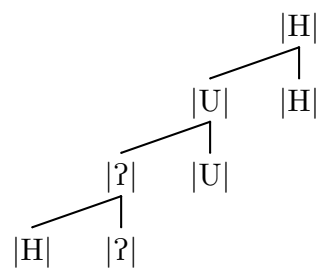

The other strand in RepBP seeking non-canonical solutions has ended up with the opposite conclusion: prosody is separable from melody, and is flat; structural relations are not primarily vertical but lateral/horizontal. This is because one way to constrain a representational model is to assume strict binarity in branching as a consequence of local dependency relations; this assumption, however, has led to less and less branching, and to what had been seen as constituents being redefined as bogus sequences with the members sandwiching empty categories. At the same time, a strict adherence to the structure preservation principle in the analysis of processes like vowel-zero alternations and compensatory lengthening lends extra motivation for positing empty positions. The end result is Strict $\mathbf{C V}$ phonology or CVCV phonology (Lowenstamm 1996), merging the skeleton and syllable structure into a single tier of strictly alternating $\mathrm{C}$ and V slots, in which parametrically licensed empty positions produce surface clusters and edge effects, and lateral forces (government and/or licensing, depending on the version of the theory) are responsible for asymmetries in phonological strength, resulting in representations such as those in (10). All this is typically accompanied by some relatively ordinary form of ET for the representation of melody.

${ }^{20}$ The structure is dominated by Closure. $\mathrm{N}=$ Noise, $\mathrm{VO}=$ Vocalic Onset. 
(10) Strict CV representations with empty positions licensed by trochaic government (Polgárdi 2015, 387)
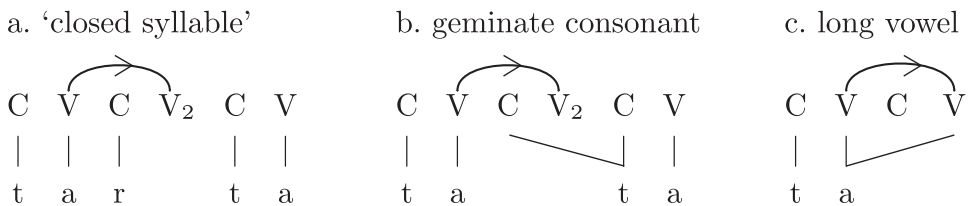

Among the proponents of this 'flat'/'horizontal' model, perhaps the most salient is Scheer (a highly prolific author with numerous publications including a thick monograph on CVCV - Scheer 2004); but there is also a group of other France-based researchers belonging to the CNRS (Centre National de la Recherche Scientifique, or National Centre for Scientific Research) e.g., Dabouis et al. (2020); Faust (2020); Lahrouchi \& Ségéral (2010); Enguehard \& Luo (2020); Passino (2020). Other work in CVCV phonology includes Balogné Bérces (a number of publications incl. 2015) and Ulfsbjorninn (a number of publications; most recently, 2020) - see further references in Scheer \& Cyran (2017). One of two sub-branches of the theory proposes an alternative segmentation of the skeleton (VC phonology - Szigetvári 1999), the other assumes the non-uniformity of word edges (Loose CV phonology - Polgárdi 1998 et seq.; recently, 2015). The diagrams in (11) demonstrate the analysis of a surface CVCV string (as well as surface 'ambisyllabicity') in GP2.0 and Strict CV Phonology for a comparison of 'vertical' (11a) and 'horizontal' (11b) approaches. The reader is invited to also compare these representations to that of city in DP in (8) above.

(11) A CVCV string in GP2.0 and in Strict CV Phonology

a. hippie in GP2.0 (Pöchtrager 2006, 131)

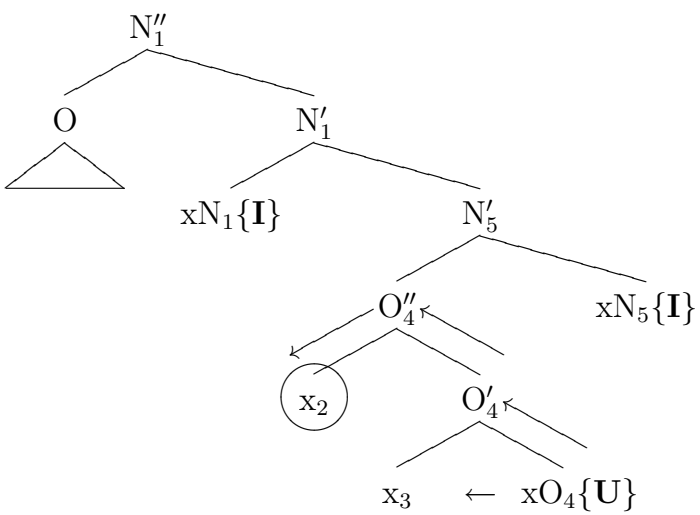


b. city in Strict CV Phonology (Balogné Bérces 2015, 151) ${ }^{21}$

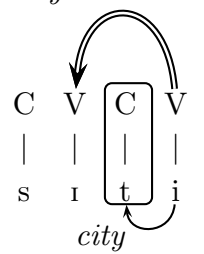

Of course, GP and GP-related approaches are not alone on the current scene of RepBP - other, non-GP representational frameworks also exist. For instance, the Toronto-School-type expanded segmental representations mentioned above form an aspect of RepBP, as does the CVX theory of syllable structure (Duanmu various publications, recently 2011) which proposes that universally the maximal syllable size in languages is CVX, where the $\mathrm{X}$ variable can be realised as either a $\mathrm{V}$ (to yield CVV) or a $\mathrm{C}$ (to yield CVC). This radically restrictive template can be maintained due to the monosegmental analysis of many consonant sequences traditionally taken to be clusters, via non-exhaustive syllabification of edge consonants, and by assuming that any extra $\mathrm{C}$ outside the $\mathrm{VX}$ window is a potential onset for a vowel in a vowel-initial suffix. Although similarly intriguing proposals regularly emerge in current research on suprasegmental structure, the theoretical frameworks introduced above retain a dominant position in purely representational phonology.

\section{Conclusion}

We have seen that the palette of phonological theory at the end of the second decade of the 21st century is characterised by a 'healthy diversity'. Most probably, the reason for this (in formal phonology at least) is that the enterprise the generative programme in linguistics sets out to pursue aims to cover such a multifaceted phenomenon that it necessitates a similar multifacetedness of approach, and requires considerable flexibility in decisions about what exactly falls under the rubric of the object of study - even when it is only phonology (or only its representational aspect) that is within the scope.

${ }^{21}$ Simple arrows indicate government, double arrows denote licensing. The IPA symbols on the melodic tier are shorthand for phonological expressions in ET. 


\section{Acknowledgments}

The authors are grateful to Pázmány Péter Catholic University's grant no. KAP18-510061.2-BTK for funding Katalin Balogné Bérces's strategic trip to the University of Edinburgh.

\section{References}

Anderson, John 2011. The substance of language volume III: Phonology-syntax analogies. Oxford: Oxford University Press.

Anderson, John and Colin J. Ewen. 1987. Principles of Dependency Phonology. Cambridge: Cambridge University Press.

Backley, Phillip. 2011. An introduction to Element Theory. Edinburgh: Edinburgh University Press.

Backley, Phillip. 2012. Variation in element theory. Linguistic Variation 12. 57-102.

Balogné Bérces, Katalin. 2015. Consonant lenition inside and outside the "minimal foot": A Strict CV Phonology analysis. Acta Linguistica Hungarica 52. 141-155.

Balogné Bérces, Katalin. 2019. Fonológiai variáció és generatív nyelvelmélet [Phonological variation and generative linguistics]. Általános Nyelvészeti Tanulmányok 31. 29-56.

Bermúdez-Otero, Ricardo and Patrick Honeybone. 2006. Phonology and syntax: A shifting relationship. Lingua 116. 543-561.

Blaho, Sylvia and Szilárd Szentgyörgyi. 2003. Pre-sonorant voicing in Slovak: The treatment of a derived environment effect in OT. In J. Spenader, A. Eriksson and O. Dahl (eds.) Proceedings of the Stockholm workshop on Variation within Optimality Theory. Stockholm: Stockholm University. 39-46.

Böhm, Roger and Harry van der Hulst (eds.). 2018. Substance-based grammar: The (ongoing) work of John Anderson. Amsterdam \& Philadelphia: John Benjamins.

Bybee, Joan L. 2001. Phonology and language use (Cambridge Studies in Linguistics 94). Cambridge: Cambridge University Press.

Carvalho, Joaquim Brandão de. 2011. Contrastive hierarchies, privative features, and Portuguese vowels. Revista de Estudos Linguísticos da Universidade do Porto 1. 51-66.

Cavirani, Edoardo and Marc van Oostendorp. 2020. A theory of the theory of vowels. In Nasukawa (2020, 37-56).

Chabot, Alex. to appear. Features and phonetic substance: Implications for phonological theory. Special issue of Canadian Journal of Linguistics.

Charette, Monik. 2017. The internal TR clusters of Acadian French: A hint from schwa. In G. Lindsey and A. Nevins (eds.) Sonic signatures: Studies dedicated to John Harris. Amsterdam \& Philadelphia: John Benjamins. 18-32.

Chomsky, Noam and Morris Halle. 1968. The sound pattern of English. New York: Harper \& Row.

Cyran, Eugeniusz. 2014. Between phonology and phonetics. Polish voicing. Boston \& Berlin: De Gruyter Mouton.

Dabouis, Quentin, Guillaume Enguehard, Jean-Michel Fournier and Nicola Lampitelli. 2020. The English "Arab Rule" without feet. Acta Linguistica Academica 67. 
Dresher, Bezalel Elan. 2009. The contrastive hierarchy in phonology. Cambridge: Cambridge University Press.

Duanmu, San. 2011. The CVX theory of syllable structure. In C. E. Cairns and E. Raimy (eds.) Handbook of the syllable. Leiden: Brill. 99-127.

Enguehard, Guillaume and Xiaoliang Luo. 2020. A note on the strength of vowels. Acta Linguistica Academica 67.

Faust, Noam. 2020. The inflection of tigre weak-final and strong verbs. Acta Linguistica Academica 67.

Faust, Noam and Paul Smolensky. 2017. Activity as an alternative to autosegmental association. Paper presented at the 25th Manchester Phonology Meeting.

Faust, Noam and Francesc Torres-Tamarit. 2017. Stress and final /n/ deletion in Catalan: Combining Strict CV and OT. Glossa 63. 1-23.

Hall, Daniel Currie. 2007. The role and representation of contrast in phonological theory. Doctoral dissertation. University of Toronto.

Hannahs, S. J. and Anna R. K. Bosch (eds.). 2017. The Routledge handbook of phonological theory. London: Routledge.

Harris, John. 1994. English sound structure. Oxford \& Cambridge, MA: Blackwell.

Harris, John and Jonathan Kaye. 1990. A tale of two cities: London glottalling and New York City tapping. The Linguistic Review 7. 251-274.

Honeybone, Patrick. 2005. Diachronic evidence in segmental phonology: The case of obstruent laryngeal specifications. In M. van Oostendorp and J. van de Weijer (eds.) The internal organization of phonological segments. Berlin \& New York: Mouton de Gruyter. 319-354.

Honeybone, Patrick. 2011. Lost in linguistics: A guide to the current landscape of linguistic theory. Phonology. Handout for a minicourse held at the University of Oslo, October 2011.

Huber, Dániel and Katalin Balogné Bérces. 2010. [voice] and/versus [spread glottis] in the modified Leiden model. Acta Linguistica Hungarica 57. 444-457.

Hulst, Harry van der. 1994. Radical CV Phonology: The locational gesture. UCL Working Papers in Linguistics 6. 439-477.

Hulst, Harry van der. 2011. Dependency-based phonologies. In J. A. Goldsmith, J. Riggle and A. C. L. Yu (eds.) The handbook of phonological theory (Second edition). Malden, MA \& Oxford: Wiley-Blackwell. 533-570.

Hulst, Harry van der. 2018. Asymmetries in vowel harmony: A representational account. Oxford: Oxford University Press.

Hulst, Harry van der and Jeroen van de Weijer. 2017. Dependency Phonology. In Hannahs \& Bosch (2017, 325-35).

Hulst, Harry van der and Jeroen van de Weijer. 2018. Degrees of complexity in phonological segments. In Böhm \& van der Hulst (2018, 391-436).

Huszthy, Bálint. 2016. Italian as a voice language without voice assimilation. In K. Bellamy, E. Karvovskaya, M. Kohlberger and G. Saad (eds.) ConSOLE XXIV: Proceedings of the 24th ConSOLE. Leiden: Leiden University Centre for Linguistics. 428-452.

Kaye, Jonathan. 1992. On the interaction of theories of Lexical Phonology and theories of phonological phenomen. In W. U. Dressler, H. C. Luschützky, O. E. Pfeiffer and J. R. Rennison (eds.) Phonologica 1988. Cambridge: Cambridge University Press. 141-155. 
Kaye, Jonathan, Jean Lowenstamm and Jean-Roger Vergnaud. 1985. The internal structure of phonological elements: A theory of charm and government. Phonology Yearbook 2. 305-328.

Kaye, Jonathan, Jean Lowenstamm and Jean-Roger Vergnaud. 1990. Constituent structure and government in phonology. Phonology 7. 193-231.

Kula, Nancy C. 2002. The phonology of verbal derivation in Bemba. Doctoral dissertation. University of Leiden.

Kula, Nancy C. 2012. On the representation of tone in Element Theory. In E. Cyran, H. Kardela and B. Szymanek (eds.) Sound, structure and sense. Studies in memory of Edmund Gussmann. Lublin: Wydawnictwo KUL. 353-367.

Kula, Nancy C. and Xiaoxi Liu. 2020. Multi-layered recursive representations for depressors. In Nasukawa (2020, 143-180).

Lahrouchi, Mohamed and Philippe Ségéral. 2010. Peripheral vowels in Tashlhiyt Berber are phonologically long: Evidence from Tagnawt, a secret language used by women. Brill's Journal of Afroasiatic Languages and Linguistics 2. 202-221.

Liu, Xiaoxi. 2017. A multi-layered approach to depressor effects. Paper presented at GPRT 2017, PPCU, Budapest.

Lodge, Ken. 2009. Fundamental concepts in phonology: Sameness and difference. Edinburgh: Edinburgh University Press.

Lowenstamm, Jean. 1996. CV as the only syllable type. In J. Durand and B. Laks (eds.) Current trends in phonology. Models and methods. Salford: European Studies Research Institute, University of Salford Publications. 419-441.

McCarthy, John. 2001. A thematic guide to Optimality Theory. Cambridge: Cambridge University Press.

Nasukawa, Kuniya. 2011. Representing phonology without precedence relations. English Linguistics 28. 278-300.

Nasukawa, Kuniya. 2017. Acoustic prominence and phonological head-dependent structure. Paper presented at RIL HAS, Budapest, 16 Nov 2017.

Nasukawa, Kuniya. 2019. Phonetic linearisation of morpheme-internal phonological structure. Manuscript. https://tinyurl.com/ta27.jpz

Nasukawa, Kuniya (ed.). 2020. Morpheme-internal recursion in phonology. Berlin \& New York: Mouton de Gruyter.

Nasukawa, Kuniya and Phillip Backley. 2005. Dependency relations in Element Theory. Leiden Papers in Linguistics 2. 77-93.

Navarro, Sylvain. 2018. Rhotics and the derhoticization of English: A Dependency Phonology analysis. In Böhm \& van der Hulst (2018, 343-369).

Neef, Martin. 2018. Autonomous Declarative Phonology. In C. Behme and M. Neef (eds.) Essays on linguistic realism. Amsterdam \& Philadelphia: John Benjamins. 185-202.

Nespor, Marina and Irene Vogel. 1986. Prosodic phonology. Dordrecht: Foris.

Oostendorp, Marc van. to appear. History of phonology: Optimality Theory. In B. E. Dresher and H. van der Hulst (eds.) The Oxford handbook of the history of phonology. Oxford: Oxford University Press.

Passino, Diana. 2020. Positional factors in syllabification. Acta Linguistica Academica 67.

Petrova, Olga, Rosemary Plapp, Cathrine Ringen and Szilárd Szentgyörgyi. 2006. Voice and aspiration: Evidence from Russian, Hungarian, German, Swedish, and Turkish. The Linguistic Review 23. 1-35. 
Pierrehumbert, Janet. 2001. Exemplar dynamics: Word frequency, lenition and contrast. In J. L. Bybee and P. Hopper (eds.) Frequency and the emergence of linguistic structure. Amsterdam \& Philadelphia: John Benjamins. 137-157.

Polgárdi, Krisztina. 1998. Vowel harmony. An account in terms of government and optimality. The Hague: Holland Academic Graphics.

Polgárdi, Krisztina. 2015. Syncope, syllabic consonant formation, and the distribution of stressed vowels in English. Journal of Linguistics 51. 383-423.

Port, Robert F. and Adam P. Leary. 2005. Against formal phonology. Language 81. 927-964.

Pöchtrager, Markus Alexander. 2006. The structure of length. Doctoral dissertation. Universität Wien.

Pöchtrager, Markus Alexander. 2020. Tense? (Re)lax! A new formalisation for a controversial contrast. Acta Linguistica Academica 67.

Prince, Alan and Paul Smolensky. 1993. Optimality theory: Constraint interaction in generative grammar. Technical Report TR-2, Center for Cognitive Science, Rutgers University, New Brunswick, N.J. and Technical Report CU-CS-697-93, Department of Computer Science, University of Colorado, Boulder.

Rennison, John C. and Friedrich Neubarth. 2003. An x-bar theory of Government Phonology. In S. Ploch (ed.) Living on the edge: 27 papers in honour of Jonathan Kaye. Berlin \& New York: Mouton de Gruyter. 95-130.

Sandstedt, Jade Jørgen. 2018. Feature specifications and contrast in vowel harmony: The orthography and phonology of Old Norwegian height harmony. Doctoral dissertation. University of Edinburgh.

Schane, Sanford A. 1984. The fundamentals of Particle Phonology. Phonology Yearbook 1. $129-155$.

Scheer, Tobias. 2004. A lateral theory of phonology. Vol 1: What is CVCV, and why should it be? Berlin \& New York: Mouton de Gruyter.

Scheer, Tobias. 2015. How diachronic is synchronic grammar? Crazy rules, regularity, and naturalness. In P. Honeybone and J. Salmons (eds.) The Oxford handbook of historical phonology. Oxford: Oxford University Press. 313-336.

Scheer, Tobias. 2019. Phonetic arbitrariness: A cartography. Phonological Studies 22. $105-118$.

Scheer, Tobias and Eugeniusz Cyran. 2017. Syllable structure in Government Phonology. In Hannahs \& Bosch (2017, 262-292).

Scheer, Tobias and Nancy C. Kula. 2017. Government Phonology: Element Theory, conceptual issues and introduction. In Hannahs \& Bosch (2017, 226-261).

Schwartz, Geoffrey. 2017. Formalizing modulation and the emergence of phonological heads. Glossa 2. 81.

Schwartz, Geoffrey. 2019. Refining representations for L2 phonology. Second Language Research Online first.

Sebregts, Koen. 2017. Twenty-five years of the mfm, twenty-five years of phonology. Paper presented at the 25th Manchester Phonology Meeting.

Szigetvári, Péter. 1999. VC Phonology: A theory of consonant lenition and phonotactics. Doctoral dissertation. Eötvös Loránd University/MTA, Budapest. 
Szigetvári, Péter. 2020. Emancipating lenes: A reanalysis of English obstruent clusters. Acta Linguistica Academica 67.

Tifrit, Ali and Laurence Voeltzel. 2016. Revis(it)ing French palatalization. Glossa 1. 1-20.

Torres-Tamarit, Francesc and Ben Hermans. 2017. Branchingness constraints on heads and dependents in Munster Irish stress. Glossa 2. 1-19.

Traunmüller, Hartmut. 1994. Conventional, biological, and environmental factors in speech communication: A modulation theory. Phonetica 51. 170-183.

Uffmann, Christian. 2011. Constraint-based phonology. In N. C. Kula, B. Botma and K. Nasukawa (eds.) The Continuum companion to phonology. London \& New York: Continuum. 174-201.

Ulfsbjorninn, Shanti. 2020. Segment-zero alternations in Galician definite article allomorphy: Floating consonants at the left edge of morphemes. Acta Linguistica Academica 67.

Vaux, Bert. 2008. Why the phonological component must be serial and rule-based. In B. Vaux and A. Nevins (eds.) Rules, constraints, and phonological phenomena. Oxford: Oxford University Press. 20-61.

Zimmermann, Eva. 2017. Morphological length and prosodically defective morphemes. Oxford: Oxford University Press.

Živanović, Sašo. 2020. Branching onsets. Acta Linguistica Academica 67.

Open Access. This is an open-access article distributed under the terms of the Creative Commons Attribution 4.0 International License (https://creativecommons.org/licenses/ by/4.0), which permits unrestricted use, distribution, and reproduction in any medium, provided the original author and source are credited, a link to the CC License is provided, and changes - if any - are indicated. (SID_1) 
